\title{
A case report of intrapulmonary schwannoma
}

\author{
Takuro Yukawa $\cdot$ Katsuhiko Shimizu $\cdot$ \\ Yuji Hirami • Riki Okita • Shinsuke Saisho • \\ Ai Maeda $\cdot$ Koichiro Yasuda $\cdot$ Masao Nakata
}

Received: 7 February 2013/ Accepted: 6 March 2013/Published online: 23 March 2013

(c) The Author(s) 2013. This article is published with open access at Springerlink.com

\begin{abstract}
A 38-year-old man without any symptoms was admitted to our institution because of an abnormal shadow found incidentally on a chest X-ray. Chest computed tomography showed a round mass in the lingular segment of the left upper lobe. Lingular segmentectomy was performed, and the histopathological diagnosis was intrapulmonary schwannoma. Immunohistochemical staining revealed a positive result for S-100 protein and negative results for CD34 and desmin. We report this case of intrapulmonary schwannoma, which is extremely rare.
\end{abstract}

Keywords Intrapulmonary schwannoma $\cdot$ Neurogenic tumor

\section{Introduction}

Schwannoma may arise from any peripheral nerve and is often found in the chest wall and posterior mediastinum. However, case reports of intrapulmonary schwannoma are extremely rare. We report a case of primary intrapulmonary schwannoma.

\section{Case}

A 38-year-old man was referred to our institution because of an abnormal shadow found incidentally on the chest

T. Yukawa $(\bowtie) \cdot$ K. Shimizu · Y. Hirami · R. Okita •

S. Saisho $\cdot$ A. Maeda $\cdot$ K. Yasuda - M. Nakata

Department of General Thoracic Surgery,

Kawasaki Medical School, 577 Matsushima, Kurashiki,

Okayama 701-0192, Japan

e-mail: tyukawa@med.kawasaki-m.ac.jp
$\mathrm{X}$-ray. His past medical history was insignificant. The plain chest X-ray showed a mass lesion in the left middle zone. The mass was about $3 \mathrm{~cm}$ in diameter. Chest computed tomography $(\mathrm{CT})$ showed a round and homogeneous mass $25 \times 18 \mathrm{~mm}$ in size with a well-defined margin in the lingular segment of the left upper lobe (Fig. 1a). 18-Fluorodeoxy-glucose (FDG) positron-emission tomography (PET) showed no accumulation in the tumor (Fig. 1b). The CT and FDG-PET findings suggested the possibility of a benign tumor or a low-grade malignancy. As a malignant tumor could not be definitively ruled out, we performed lingular segmentectomy.

Macroscopic examination of the resected specimen showed a well-demarcated round tumor in the lung, without any evidence of invasion of the surrounding tissues. The cut surface was yellowish-white in color (Fig. 2a). Microscopic examination revealed proliferation of elongated tumor cells having spindle-shaped nuclei, with cellular palisading (Fig. 2b). No necrosis or nuclear atypia was observed. Immunohistochemical staining demonstrated positive staining of the tumor cells for S-100 protein and BCL2, but negative staining for CD34 and desmin. The histopathological diagnosis was intrapulmonary schwannoma.

\section{Discussion}

Schwannoma is one of the few truly encapsulated neoplasms of the human body, and is almost always solitary. It most commonly occurs on the flexor surfaces of the extremities, neck, mediastinum, retroperitoneum, posterior spinal roots, and cerebellopontine angle [1]. However, schwannomas are extremely rare in the lung, regardless of the patient age. Ohtsuka and colleagues [2] reported 62 patients (28 men, 34 women) aged 5-83 years, with 

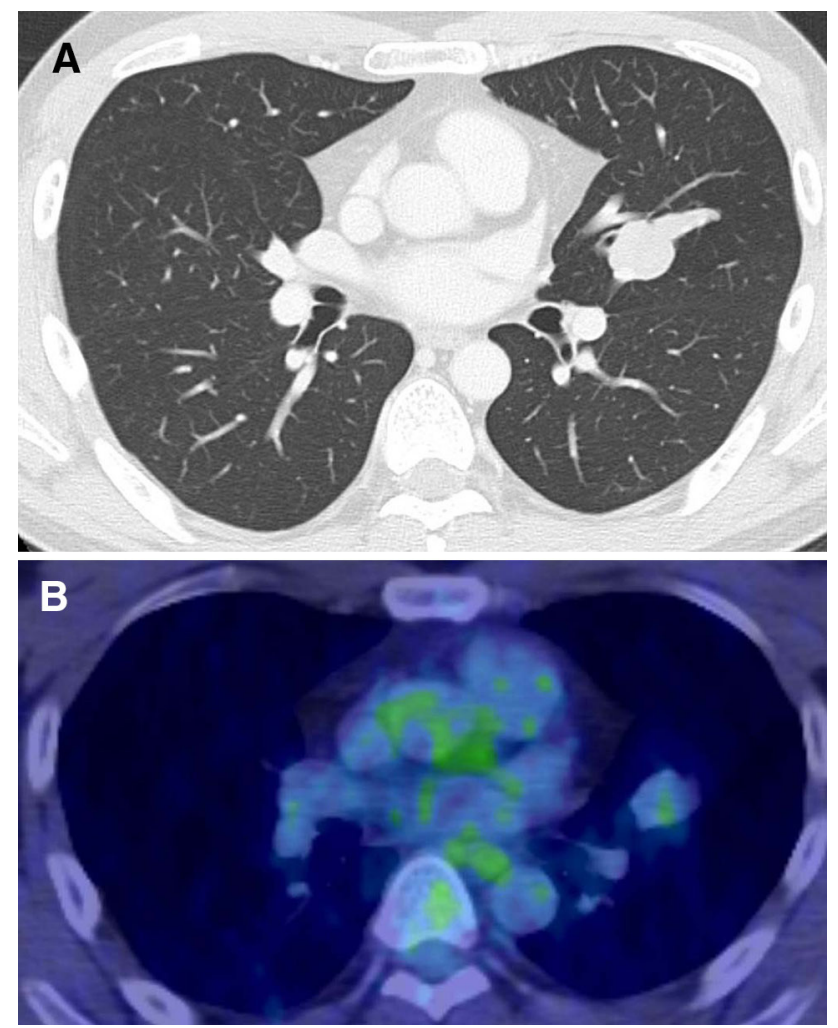

Fig. 1 a Computed tomography shows a mass with well-defined margins in the lingular segment of the left upper lobe. b 18Fluorodeoxy-glucose (FDG) positron-emission tomography (PET) showed no accumulation in the tumor

intrapulmonary or bronchial schwannomas, and stated that this neoplasm accounted for about $0.2 \%$ of all pulmonary neoplasms. In $55 \%$ of these patients, the tumor originated within the tissues in proximity to the terminal segmental bronchus.

On radiographic images, peripheral intrapulmonary schwannoma appears as a round mass with well-defined margins [2]. In patients with the tumor located proximal to a lobar bronchus, atelectasis or pneumonia may occur, associated with cough and dyspnea. About half of the patients have some symptoms; however, most patients with peripheral intrapulmonary schwannomas, as in the present case, have no symptoms [2].

Today, FDG-PET is a useful approach to differentiate malignant solitary pulmonary nodules from benign nodules. Beaulieu et al. reported the maximum standard uptake values $\left(\mathrm{SUV}_{\max }\right)$ of the 10 schwannomas ranged from 1.9 to 7.2, and the variation in the $\mathrm{SUV}_{\max }$ could be explained by the variation in cellularity [3]. However, the reason why high FDG accumulation is found in benign tumors such as schwannoma remains unclear, and a diagnostic value of FDG-PET with intrapulmonary schwannoma is not established.
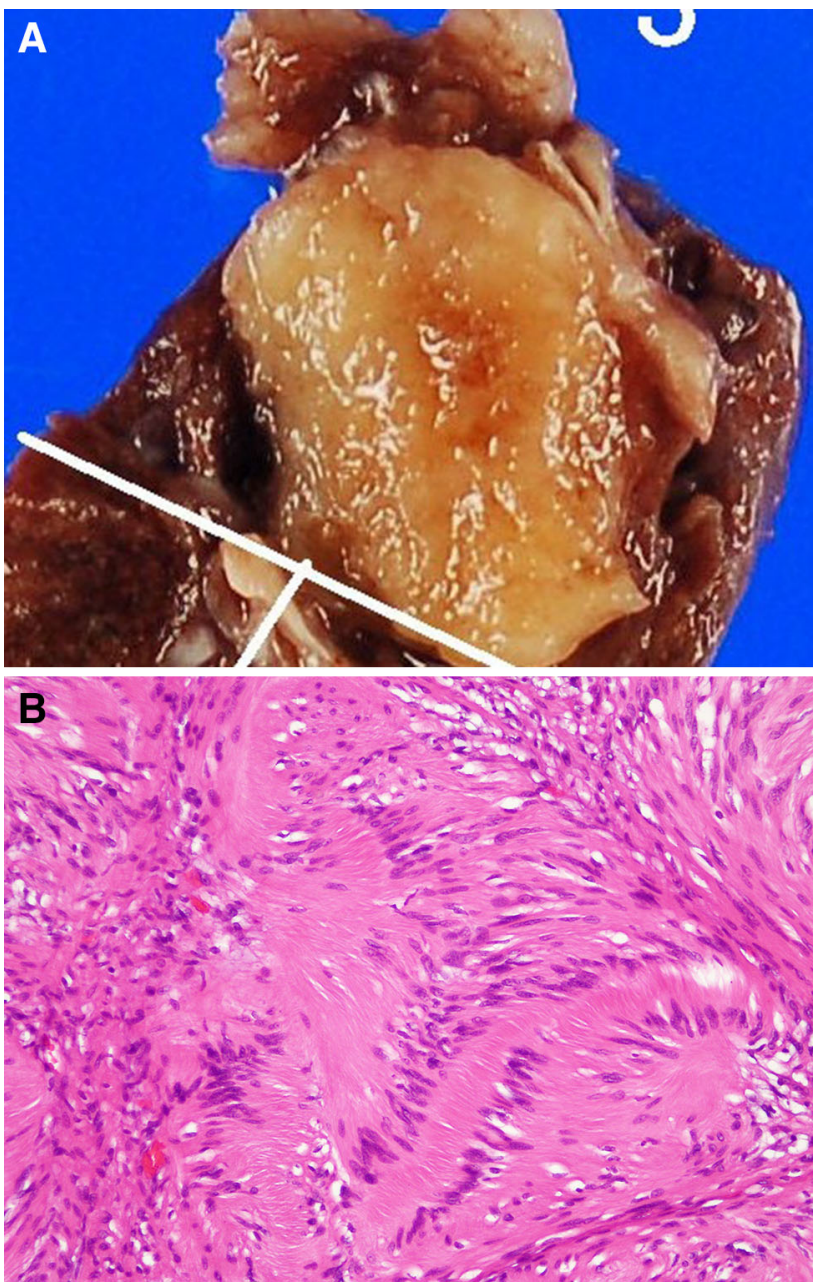

Fig. 2 a Macroscopic examination of the specimen showed a round, well-demarcated tumor in the lung, without invasion of the surrounding tissues. The cut surface was yellowish-white in color. b Microscopic examination revealed elongated tumor cells with spindle-shaped nuclei

It is reported that in rare instances, schwannomas may undergo malignant transformation. The expression level of Ki67, a tumor cell proliferation marker, has been reported to be useful for determining the malignant potential of these tumors [4]. Kindblom and colleagues [4] compared the Ki67 expression levels in 26 malignant peripheral nerve sheath tumors and 24 benign nerve sheath tumors (schwannomas), and reported that significantly high density of nuclear staining was found in malignant peripheral nerve sheath tumors.

For the treatment of primary intrapulmonary schwannoma, surgical resection, intrabronchial resection with endoscopy, and yttrium aluminium garnet (YAG) laser resection have been employed [5-7]. Because of the low malignant potential of these tumors, tumor enucleation or partial lung resection is thought to be adequate, with lobectomy not being necessary. In the present case, we performed segmentectomy to accomplish complete 
resection, because we did not obtain the pathological diagnosis before the operation and the tumor was located in the central part of the superior lingular segment.

In conclusion, we had reported a case of intrapulmonary schwannoma, what is extremely rare. The symptoms and CT manifestations are nonspecific, therefore preoperative diagnosis is generally difficult.

Open Access This article is distributed under the terms of the Creative Commons Attribution License which permits any use, distribution, and reproduction in any medium, provided the original author(s) and the source are credited.

\section{References}

1. Ackerman L, Rosai J. Ackerman's surgical pathology. 8th ed. St. Louis: Mosby; 1996.
2. Ohtsuka T, Nomori H, Naruke T, Orikasa H, Yamazaki K, Suemasu K. Intrapulmonary schwannoma. Jpn J Thorac Cardiovasc Surg. 2005;53:154-6.

3. Ushiyama T, Katsuda E, Tanaka T, Numanami H, Takahashi E, Baba K, et al. 18F-Fluorodeoxyglucose uptake and apparent diffusion coefficient in lung schwannoma. Clin Imaging. 2012;36: 65-7.

4. Kindblom LG, Ahlden M, Meis-Kindblom JM, Stenman G. Immunohistochemical and molecular analysis of p53, MDM2, proliferating cell nuclear antigen and Ki67 in benign and malignant peripheral nerve sheath tumors. Virchows Arch. 1995; 427:19-26.

5. Matuskura T, Itoi S, Okada K, Kuwabara M. Tracheoplasty with an intercostals pedicle flap for tracheal neurilemmoma: a case report. Jpn J Thorac Cardiovasc Surg. 1998;46:785-8.

6. Hasumi T, Kondo T, Sagawa M, Sugita M, Saito Y, Fujimura S. A case of bronchial neurinoma treated with bronchofiberscopic electrosurgery and right S6 sleeve segmentectomy. Nippon Kyobu Geka Gakkai Zasshi. 1994;42:393-8.

7. Feldhaus RJ, Anene C, Bogard P. A rare endobronchial neurilemmoma. Chest. 1989;95:461-2. 